\title{
Heating and Efficiency Comparison of a Fischer-Tropsch (FT) Fuel, JP-8+100, and Blends in a Three-Cup Combustor Sector
}

\author{
Anna E. Thomas, ${ }^{1}$ Nikita T. Saxena, ${ }^{2}$ Dale T. Shouse, ${ }^{3}$ Craig Neuroth, ${ }^{3}$ \\ Amy Lynch, ${ }^{3}$ Charles W. Frayne, ${ }^{3}$ Jeffrey S. Stutrud, ${ }^{3}$ Edwin Corporan, ${ }^{3}$ \\ Terry Hankins, ${ }^{3}$ and Robert C. Hendricks ${ }^{4}$ \\ ${ }^{1}$ Chemical Engineering Department, Georgia Institute of Technology, Atlanta, GA 30332, USA \\ ${ }^{2}$ Biomedical Engineering Department, Tufts University, Medford, MA 02155, USA \\ ${ }^{3}$ Turbine Engine Division, AFRL/WPAFB, Wright-Patterson Air Force Base, OH 45433, USA \\ ${ }^{4}$ NASA Glenn Research Center, Cleveland, OH 44135, USA \\ Correspondence should be addressed to Robert C. Hendricks, robert.c.hendricks@grc.nasa.gov \\ Received 27 September 2012; Accepted 15 October 2012 \\ Academic Editors: B. Chan and F. Liu
}

Copyright ( $\odot 2012$ Anna E. Thomas et al. This is an open access article distributed under the Creative Commons Attribution License, which permits unrestricted use, distribution, and reproduction in any medium, provided the original work is properly cited.

In order to realize alternative fueling for military and commercial use, industry guidelines be met. These aviation fueling requirements are outlined in MIL-DTL-83133F(2008) or ASTM D 7566-Annex standards and are classified as "drop-in" fuel replacements. This paper provides combustor performance data for synthetic-paraffinic-kerosene- (SPK-) type (Fisher-Tropsch (FT)) fuel and blends with JP8+100, relative to JP-8+100 as baseline fueling. Data were taken at various nominal inlet conditions: $75 \mathrm{psia}(0.52 \mathrm{MPa})$ at $500^{\circ} \mathrm{F}(533 \mathrm{~K}), 125 \mathrm{psia}(0.86 \mathrm{MPa})$ at $625^{\circ} \mathrm{F}(603 \mathrm{~K}), 175 \mathrm{psia}(1.21 \mathrm{MPa})$ at $725^{\circ} \mathrm{F}(658 \mathrm{~K})$, and $225 \mathrm{psia}$ $(1.55 \mathrm{MPa})$ at $790 \mathrm{~F}(694 \mathrm{~K})$. Combustor performance analysis assessments were made for the change in flame temperatures, combustor efficiency, wall temperatures, and exhaust plane temperatures at 3\%, 4\%, and 5\% combustor pressure drop (\%P) for fuel:air ratios $(F / A)$ ranging from 0.010 to 0.025 . Significant general trends show lower liner temperatures and higher flame and combustor outlet temperatures with increases in FT fueling relative to JP8+100 fueling. The latter affects both turbine efficiency and blade/vane life. In general, 100\% SPK-FT fuel and blends with JP-8+100 produce less particulates and less smoke and have lower thermal impact on combustor hardware.

\section{Introduction}

Finding an alternative fuel for aviation application requires a fuel feedstock with sustainable supply at a low cost with low or no negative environmental impact. The requirements for these "drop-in" fuel replacements are outlined in the MIL-DTL-83133F(2008) or ASTM D 7566-Annex, approved standards for military and civil use, respectively. Alternate jet fuels must be compatible with current engines and aircraft fuel handling systems in order to reduce the need for new systems to accommodate new fuels that may perform differently than the currently used petroleum fuels.

Even proven alternate fuels face tough issues such as secure, sustainable productivity at competitive pricing. Recently, the Federal Aviation Administration (FAA) announced the support of eight companies conducting research into commercial jet fuel alternatives that conform to ASTM D 7566-Annex and are based on resources readily available in the United States [1]. One of the ideas being explored is to produce aviation fuels from carbon monoxide given off by industrial waste gases that would otherwise add to atmospheric pollution. Another idea is to explore the conversion from cellulosic and conventional plant sugars to fuels. Others involve in the development of catalysts to convert different carbon sources into fuels in small-scale reactors to serve as distributed fuel production sources. Currently, the biofuels used by the US Navy cost about $\$ 26 /$ gal $(\$ 6.87 / \mathrm{L})[2]$. The money that the FAA is funneling into these projects could boost the production of costeffective fuels from biomass and waste feedstocks to afford 
TABLE 1: Combustor efficiency data summary $\left[(P, T)_{\text {inlet }}=[75\right.$ psia $\left.\left.(0.52 \mathrm{MPa}), 500^{\circ} \mathrm{F}(533 \mathrm{~K})\right]\right]$.

\begin{tabular}{|c|c|c|c|c|c|c|}
\hline$\% \Delta P$ & $3 \%$ & & $4 \%$ & & $5 \%$ & \\
\hline$F / A$ & $0.010-0.020$ & 0.025 & $0.010-0.020$ & 0.025 & $0.010-0.020$ & 0.025 \\
\hline Fuel & \multicolumn{6}{|c|}{ Efficiency, \% } \\
\hline JP-8 & 99.61 & 99.32 & 99.56 & 99.10 & 99.46 & 99.20 \\
\hline $50: 50$ & 99.65 & 99.24 & 99.56 & 99.09 & 99.46 & 98.90 \\
\hline FT & 99.66 & 99.20 & 99.58 & 98.96 & 99.48 & 98.87 \\
\hline Average & 99.64 & 99.25 & 99.56 & 99.05 & 99.47 & 98.99 \\
\hline St. Dev. & 0.024 & 0.058 & 0.011 & 0.080 & 0.013 & 0.181 \\
\hline
\end{tabular}

a potential for commercial and military aviation fueling. Yet to date, the alternate fuels industry's competitive costs and productivity have not responded to feedstock restraints, incentives, subsidies, or mandates, and compliance taxes are passed to consumers [3].

Adopting alternate fuels and fuel blends requires the use of fuel-flexible systems (combustors and engines) without sacrificing performance requirements. For military aviation, an alternative for traditional fuel for gas turbine and diesel systems is required. However, in many proposed alternates, the lack of sufficient amounts of aromatics that swell some fuel system seals and sulfur, which provides fuel injection pump lubricity, has the potential to reduce design component useful life [4]. For these fuels, additives are needed to increase useful component life while maintaining the performance. It is thought that FT-type fuels can support gas turbine engines at similar levels as well as have a potential use for diesel systems.

This paper provides preliminary combustor performance data for SPK-type FT fuel and blends relative to pure JP$8+100$ (herein referred to as "JP-8"), the currently used aviation fuel. Data for "Combustor A," a three-cup sector representative of current engine combustor technology (see CFD images [5], proprietary details withheld), were taken at $0 \%, 50 \%$, and $100 \%$ FT fueling (denoted as JP-8, 50:50, and $\mathrm{FT}$, resp.) with varied parameters of fuel: air ratio $(F / A)$, percent combustor pressure drop $(\% \Delta P)$, and absolute pressure. The data collected show that higher combustor operating temperatures have the potential to enhance system efficiency, but take a toll on component life, as they have a greater impact on oxidation and failure of the materials within the combustor and turbine. A small temperature difference of combustor gas entering the turbine can both be critical to turbine life and affect efficiency; there is a need for a good balance. "Bleed air," used to cool the combustor, case, turbine blades, vanes, and nozzles, could be increased to compensate for the enhanced turbine inlet temperature; this parasitic air decreases the system efficiency but helps to maintain a reasonable turbine life.

Fuel specifications; test facility conditions, operations, schematic, and fueling system; estimates of measurement errors; combustor thermal data and postprocessing parameters of Combustor A are given in the Shouse et al. paper presented at ISROMAC 13 [6]; the computational fluid dynamics (CFD) analysis and figures of combustor geometry and flow are in the Ryder et al. paper [5] also presented there (for reader convenience, see Appendix). Compositional examination of the synthetic-paraffinic kerosene with the compositional-explicit distillation curve method is discussed in Bruno and Baibourine [7] who make a useful comparison for the heats of combustion based on molecular weight, volume, and mass.

\section{Combustor Thermal Performance}

The proprietary-geometry combustor, labeled as "Combustor A," used for data collection represents a three-cup sector of a current engine combustor technology. The Shouse et al. paper [6] outlines the results given for the 225-psia (1.55$\mathrm{MPa}$ ) inlet condition, for three fueling compositions and three $F / A$ at $3 \% \Delta P$, and this paper continues to analyze all four inlet combustor conditions at all three combustor $\Delta P$ values tested for the Fischer-Tropsch fuel blends of $0 \%, 50 \%$, and $100 \%$ with JP-8 fueling (the fuel composition ratios are liquid metered flows. The $F / A$ are calculated from emissions data.) Data were taken at various nominal inlet conditions as follows.

$$
\begin{aligned}
& \text { FT fuel composition: } 0 \%, 50 \% \text {, and } 100 \%( \pm 5 \%) \text {; } \\
& \text { pressure }(P) \text { and temperature }(T): 75 \text { psia; } \\
& (0.52 \mathrm{MPa}) \text { and } 500^{\circ} \mathrm{F}(533 \mathrm{~K}), 125 \mathrm{psia} \text {; } \\
& (0.86 \mathrm{MPa}) \text { and } 625^{\circ} \mathrm{F}(603 \mathrm{~K}), 175 \mathrm{psia} \text {; } \\
& (1.21 \mathrm{MPa}) \text { and } 725^{\circ} \mathrm{F} \quad(658 \mathrm{~K}), \text { and } 225 \text { psia } \\
& (1.55 \mathrm{MPa}) \text { and } 790^{\circ} \mathrm{F}(694 \mathrm{~K}) \\
& \text { combustor pressure drop } \triangle P: 3 \%, 4 \% \text {, and } 5 \% \text {; }
\end{aligned}
$$$$
\text { fuel : air ratios }(F / A): 0.010,0.015,0.020 \text {, and } 0.025 \text {. }
$$

The test matrix is intended to be representative of potential engine operating conditions. However, there is really no one experimental state that can be deterministic to the extent of providing variation metrics for all parameters involved within the combustor. It is for this reason that JP-8 fueling was selected to establish a baseline and all comparisons are made to that baseline for which the combustor was designed.

As to inlet pressure and temperature $(P, T)$, at altitude a $15 \mathrm{~atm}$ combustor represents a 50:1 compressor; 18:1 at $5.3 \mathrm{~atm}$. Full power is rarely used except at takeoff, and of course 15 atm would only represent a compression of $15: 1-$ not realistic in terms of today's engines, nor is 15 atm realistic relative to take-off conditions. The $(P, T)$ are representative of a compression system, relative to JP-8 at similar conditions.

Combustor performance analysis assessments were made for the change in flame temperatures $\left(T_{\text {flame }}\right)$, combustor efficiency, wall temperatures, and exhaust plane temperatures ( $\left.T_{\text {plane }}\right)$.

The combustion efficiencies do not provide enough insight for determining significant combustor changes, yet they do show a trend to decrease with increased $\% \Delta P$; thus, other aforementioned ( $T_{\text {flame }}$ and $\left.T_{\text {plane }}\right)$ parameters will also be investigated.

At $75 \mathrm{psia}(0.52 \mathrm{MPa})$ the combustion efficiency of all fuel blends are outlined in Table 1 [8]. 

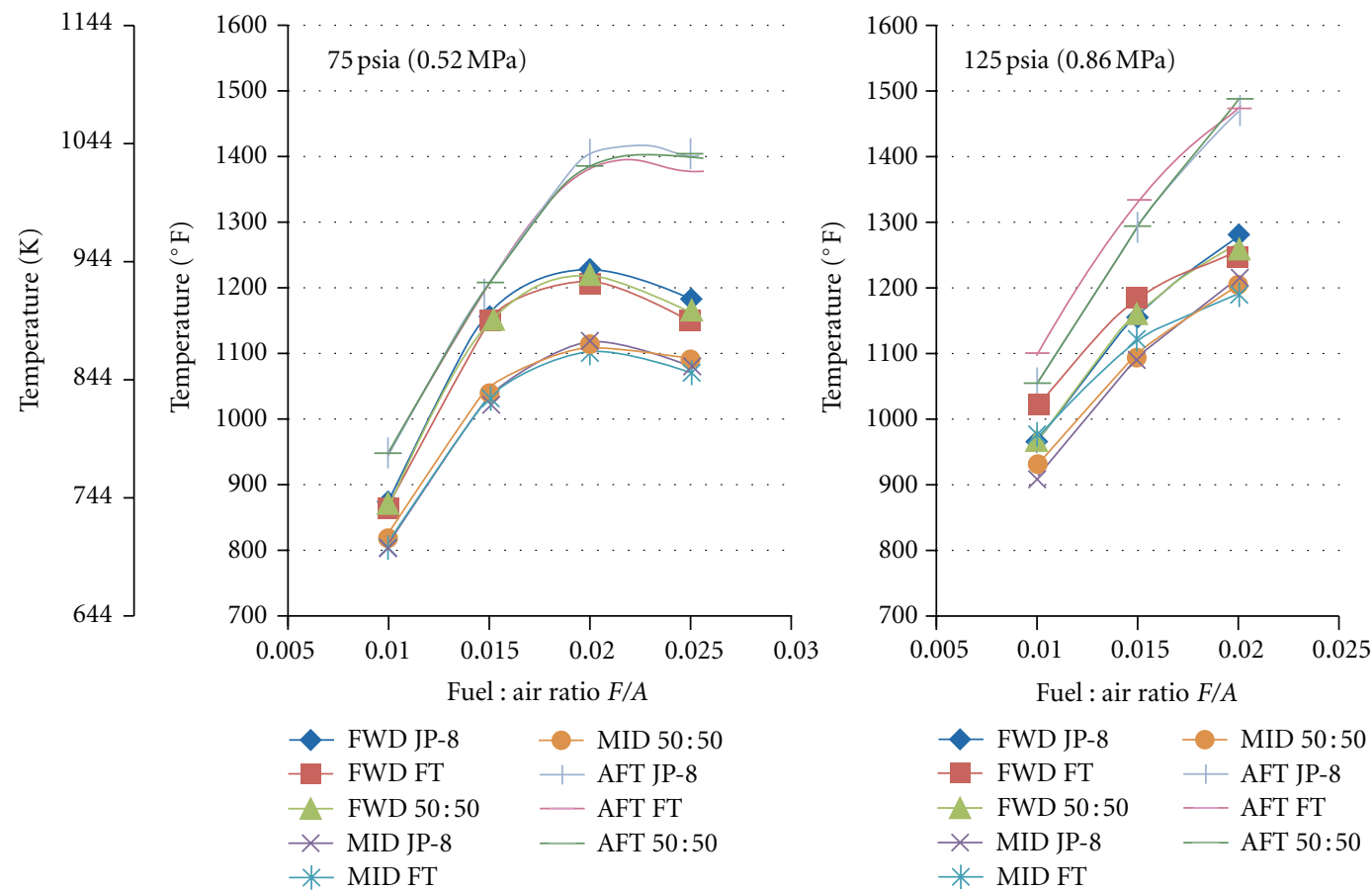

FIGURE 1: Sidewall temperature variation along the combustor (from FWD to AFT) with $F / A$ and fuel composition at $4 \% \Delta P$ for $(P, T)$ inlet $=\left[75 \mathrm{psia}(0.52 \mathrm{MPa}), 500^{\circ} \mathrm{F}(533 \mathrm{~K})\right]$ and $(P, T)_{\text {inlet }}=\left[125 \mathrm{psia}(0.86 \mathrm{MPa}), 625^{\circ} \mathrm{F}(603 \mathrm{~K})\right]$.

\section{Surface Thermal Measurements}

Thermocouples and pressure taps were placed throughout the combustion chamber to record temperature and pressure. The details of pressure drop measurements will not be presented in this paper, but it should be noted that no inconsistent pressure measurements were found. The convection-cooled liner and wall surface temperature measurements are noted as sidewall or liner (i.e., facing inside or outside of the liner).

3.1. Sidewalls. The forward, middle, and aft axial positions of the thermocouples along the sector combustor sidewalls are represented as FWD, MID, and AFT. Figure 1 represents the sidewall temperature data obtained from the $(P, T)_{\text {inlet }}$ $=\left[75 \mathrm{psia}(0.52 \mathrm{MPa}), 500^{\circ} \mathrm{F}(533 \mathrm{~K})\right]$ and $(P, T)_{\text {inlet }}=$ $\left[125 \mathrm{psia}\left(0.86 \mathrm{MPa}, 625^{\circ} \mathrm{F}(603 \mathrm{~K})\right]\right.$, runs at $4 \% \Delta P$. This figure adequately represents the sidewall temperature trends shown for all inlet pressures and $\% \Delta P$. Sidewall temperature profiles illustrate a decrease in temperature from the FWD to MID sections and an increase in temperatures from the MID to AFT along the combustor, where the temperatures are the highest. The temperatures also increase as the $F / A$ increases, the only exception being the $F / A$ of 0.025 at 75 psia $(0.52 \mathrm{MPa})$ inlet pressure, which slightly decreases in temperature relative to the $F / A$ of 0.020 . The 75 psia $(0.52 \mathrm{MPa})$ data set is the only one that includes $F / A$ of 0.025 . Data for 75 psia $(0.52 \mathrm{MPa})$ at $3 \%, 4 \%$, and $5 \% \Delta P$ at the $F / A$ of 0.025 are consistent with this trend, with insufficient data to conclude whether this is a peak in combustor temperatures around $F / A=0.020$. The sidewall temperatures depend strongly on $F / A$ and weakly on the fuel blend composition.

3.2. Unwrapped Combustor Liner. Figure 2 is a representative plot of the unwrapped liner surface temperatures, this for $F / A$ of 0.010 at $(P, T)_{\text {inlet }}\left[75 \mathrm{psia}(0.52 \mathrm{MPa}), 500^{\circ} \mathrm{F}(533 \mathrm{~K})\right]$. The term "unwrapped" refers to the normalized outside liner surface circumference ( 0 to 1 ) along with the normalized inner liner circumferential surface ( 1 to 2 ) as a continuous loop mapped onto a plane (coordinates are provided in Table 4 of the Appendix). The unwrapped combustor liner temperature profile shows a peak temperature increase measured by the thermocouple as $\% \Delta P$ increases as well as an increase in $F / A$.

The absolute inlet pressure and temperature of the system also show an effect on the peak liner temperature (Figure 2). Overall, the peaks in the temperature profile become more pronounced as $F / A$ increases. They also become more pronounced as $\% \Delta P$ increases, but $F / A$ appears to have the greater effect.

Using Figure 2, it is difficult to differentiate between the temperature differences of the varied fuel blends. By calculating the difference in temperatures read by the thermocouples at each location on the combustor for the blend and the $100 \%$ FT fuel relative to those recorded for JP-8, that is, $\Delta T=T_{\text {fuel blend }}-T_{\text {JP- } 8}$, a better sense for each fuel's performance may be obtained. Figure 3 illustrates the trends seen for the average of these temperature differences in relation to $F / A$ at $(P, T)_{\text {inlet }}=\left[125 \mathrm{psia}(0.86 \mathrm{MPa}), 625^{\circ} \mathrm{F}\right.$ $(603 \mathrm{~K})]$ and [225 psia $(1.55 \mathrm{MPa})$ and $\left.790^{\circ} \mathrm{F}(694 \mathrm{~K})\right]$ at 

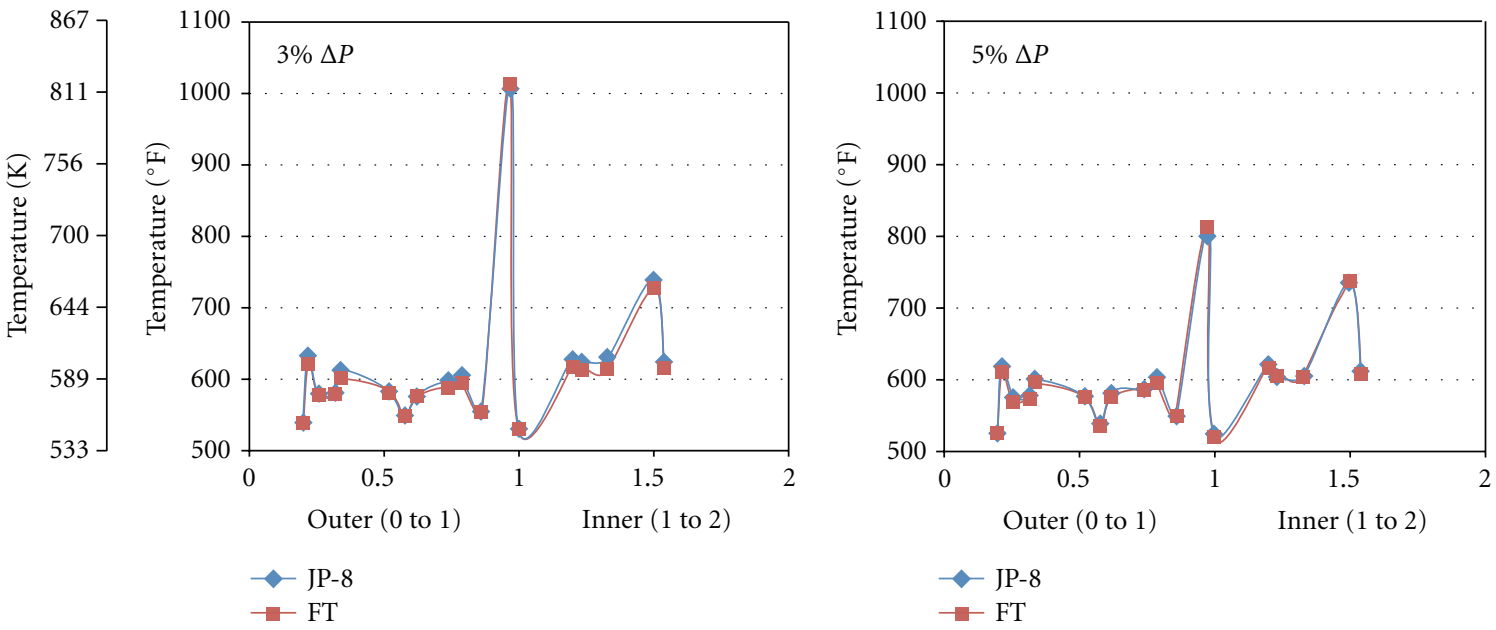

FIgURE 2: Unwrapped liner temperature profile for $F / A=0.010$ and $(P, T)_{\text {inlet }}=\left[75\right.$ psia $\left.(0.52 \mathrm{MPa}), 500^{\circ} \mathrm{F}(533 \mathrm{~K})\right]$ at $3 \%$ and $5 \% \Delta P$.
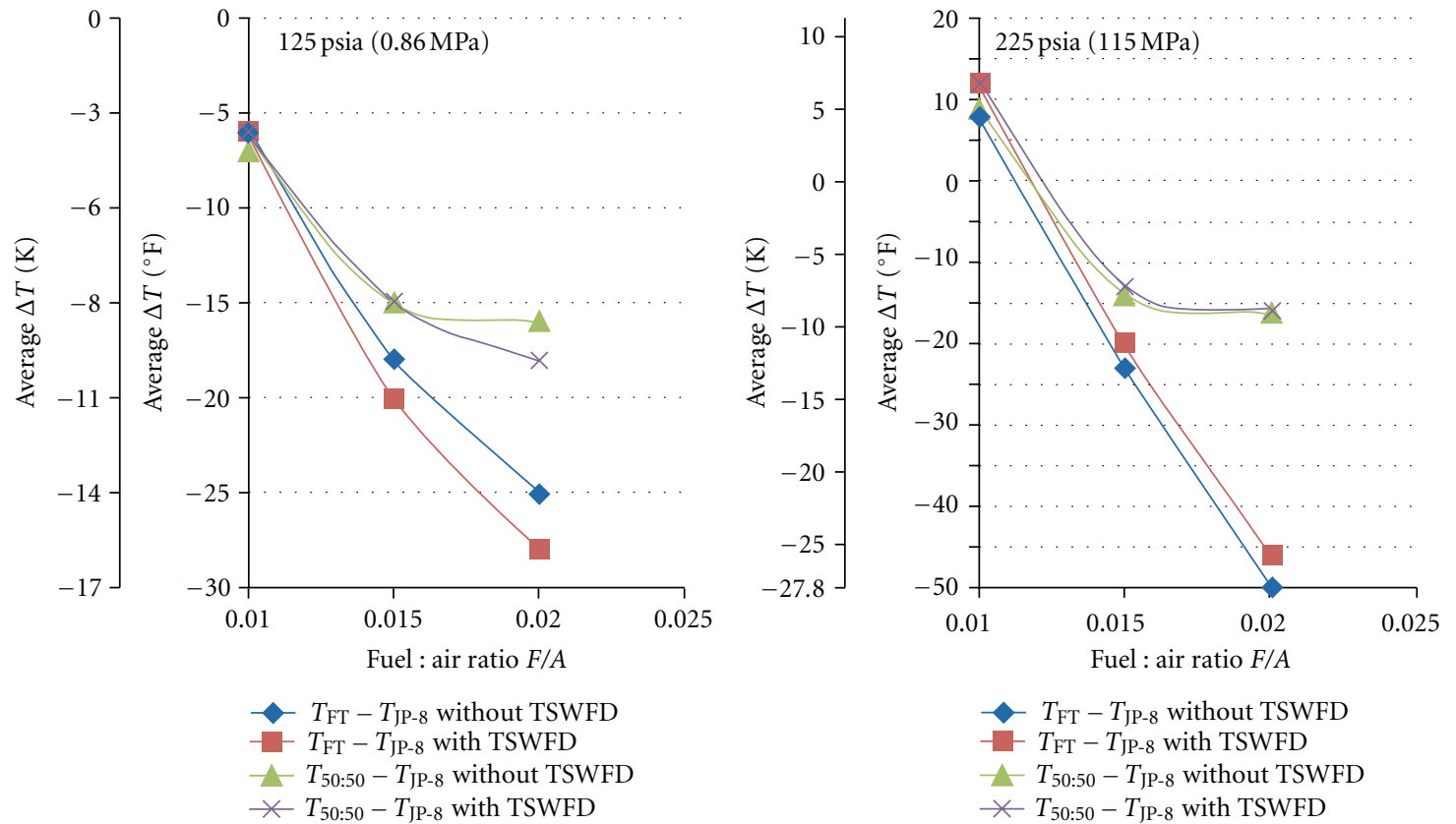

Figure 3: Average liner temperature differences $\left(\Delta T=T_{\text {fuel blend }}-T_{\mathrm{JP}-8}\right)$ versus $F / A$ for $(P, T)_{\text {inlet }}=\left[125 \mathrm{psia}(0.86 \mathrm{MPa}), 625^{\circ} \mathrm{F}(603 \mathrm{~K})\right]$ and $\left[225\right.$ psia $\left.(1.55 \mathrm{MPa}), 790^{\circ} \mathrm{F}(694 \mathrm{~K})\right]$ at $3 \% \Delta P$. The sidewall temperature at the FWD position (TSWFD) was found to be a possible outlier and was excluded from one set of averages for a better comparison. Temperatures represent combined heat transfer effects.

$3 \% \Delta P$ and gives a better picture for the heat performance of the fuels. Table 2 outlines all the average temperature differences (convective and radiation cooling) for all testing conditions.

The overall trend shows that at $F / A=0.010$, both the blend and the FT fuel generally run at higher temperatures than JP-8 for all pressure values. As the F/A increases, the $50: 50$ blend and the FT fuel temperatures decrease, ending with cooler operating temperatures relative to JP-8 at the 0.020 ratio. With respect to the increasing $F / A$, there is a larger deviation in the temperature performance of the FT and 50:50 fuels. At the higher F/A, the FT fuel runs at temperatures cooler than both the JP- 8 and the blend, illustrating that at these higher $F / A$ values the impact of FT within the blend decreases as JP-8 is increased; this is also the trend seen with flame temperatures. This would mean that at high $F / A$, the FT fuel would decrease liner temperatures relative to the JP- 8 and the $50: 50$ blend and could increase component life within the combustor and yet not the turbine. Also, greater temperature differences are shown for higher inlet pressures and temperatures.

\section{Combustion Exhaust Rake Temperature}

The exhaust plane temperature trends are illustrated in Figure 4. These temperature profiles represent data-averaged 
TABLE 2: Average unwrapped liner temperature differences ${ }^{\mathrm{a}, \mathrm{b}}:$ FT fuel and $50: 50$ blend with respect to JP-8+100 $\left(T_{\text {fuel blend }}-T_{\text {JP-8 }}\right)\left({ }^{\circ} \mathrm{F}\right)[\Delta T$ $\left.\left({ }^{\circ} \mathrm{F}\right)=1.8 \Delta T(\mathrm{~K})\right]$.

\begin{tabular}{|c|c|c|c|c|c|c|c|c|c|c|c|c|c|}
\hline \multirow[b]{2}{*}{ Inlet pressure } & \multirow[b]{2}{*}{$\% \Delta P$} & \multicolumn{3}{|c|}{$F / A=0.010$} & \multicolumn{3}{|c|}{$F / A=0.015$} & \multicolumn{3}{|c|}{$F / A=0.020$} & \multicolumn{3}{|c|}{$F / A=0.025$} \\
\hline & & JP-8 & FT & $50: 50$ & JP-8 & FT & $50: 50$ & JP-8 & FT & $50: 50$ & JP-8 & FT & $50: 50$ \\
\hline \multirow{3}{*}{$\begin{array}{l}75 \text { psia } \\
(0.52 \mathrm{MPa})\end{array}$} & $3 \%$ & 0 & -4 & -5 & 0 & 1 & -6 & 0 & -15 & -11 & 0 & -12 & -16 \\
\hline & $4 \%$ & 0 & -2 & 0 & 0 & -2 & -2 & 0 & -9 & -7 & 0 & -12 & -8 \\
\hline & $5 \%$ & 0 & -3 & -2 & 0 & -1 & -2 & 0 & -2 & -3 & 0 & -3 & 1 \\
\hline \multirow{3}{*}{$\begin{array}{l}125 \text { psia } \\
(0.86 \mathrm{MPa})\end{array}$} & $3 \%$ & 0 & -6 & -6 & 0 & -20 & -15 & 0 & -28 & -18 & & & \\
\hline & $4 \%$ & 0 & 1 & -1 & 0 & -6 & -6 & 0 & -29 & -16 & & & \\
\hline & $5 \%$ & 0 & 6 & 2 & 0 & -10 & -5 & 0 & -23 & -11 & & & \\
\hline \multirow{3}{*}{$\begin{array}{l}175 \text { psia } \\
(1.21 \mathrm{MPa})\end{array}$} & $3 \%$ & 0 & 7 & 2 & 0 & -25 & -6 & 0 & -39 & -18 & & & \\
\hline & $4 \%$ & 0 & 1 & 0 & 0 & -13 & -10 & 0 & -22 & -14 & & & \\
\hline & $5 \%$ & 0 & 2 & 1 & 0 & -11 & -7 & 0 & -26 & -17 & & & \\
\hline \multirow{3}{*}{$\begin{array}{l}225 \text { psia } \\
(1.55 \mathrm{MPa})\end{array}$} & $3 \%$ & 0 & 12 & 12 & 0 & -20 & -13 & 0 & -46 & -16 & & & \\
\hline & $4 \%$ & 0 & 18 & 17 & 0 & -9 & -4 & 0 & -31 & -14 & & & \\
\hline & $5 \%$ & 0 & 6 & 3 & 0 & -9 & 1 & 0 & -39 & -14 & & & \\
\hline
\end{tabular}

${ }^{\mathrm{a}}(P, T)$ inlet $=\left[75 \mathrm{psia}(0.52 \mathrm{MPa}), 500^{\circ} \mathrm{F}(533 \mathrm{~K})\right],\left[125 \mathrm{psia}(0.86 \mathrm{MPa}), 625^{\circ} \mathrm{F}(603 \mathrm{~K})\right]$,

[175 psia $\left.(1.21 \mathrm{MPa}), 725^{\circ} \mathrm{F}(658 \mathrm{~K})\right]$, and [225 psia $\left.(1.55 \mathrm{MPa}), 790^{\circ} \mathrm{F}(694 \mathrm{~K})\right]$.

${ }^{\mathrm{b}} \Delta T<0$ implies cooler liner temperature.
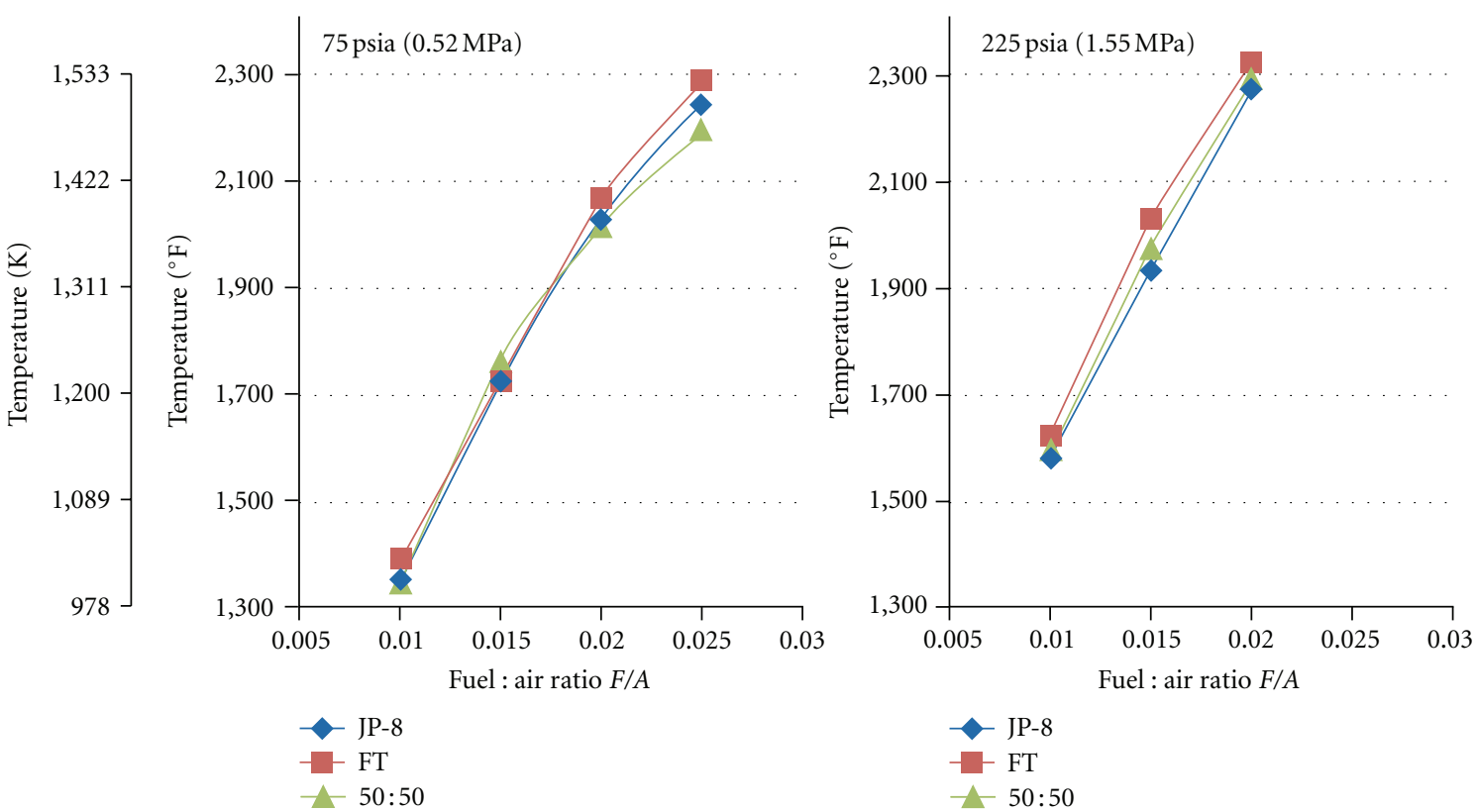

Figure 4: Variation of exhaust (combustor exit) temperatures with percent fueling as a function of $F / A$ for $(P, T)_{\text {inlet }}=[75 \mathrm{psia}(0.52 \mathrm{MPa})$ and $\left.500^{\circ} \mathrm{F}(533 \mathrm{~K})\right]$ and $\left[225 \mathrm{psia}(1.55 \mathrm{MPa}), 790^{\circ} \mathrm{F}(694 \mathrm{~K})\right]$, at $3 \% \Delta P$.

temperature values collected through the use of a temperature probe (rake) placed in the exhaust plane of the combustor. In these data, the signal from the top thermocouple was lost. For all data sets, there is a monotone increase in the exhaust plane temperature as $F / A$ is increased. The increase in $\% \Delta P$ also creates an increase in the temperature. At higher percent combustor pressure drop values and higher $F / A$, the FT fuel tends to run at higher exhaust temperatures compared to JP-8 and the blend, which also gives slightly higher temperatures. Upon further analysis, as $F / A$ increases, the FT fuel, while at higher exhaust plane temperature, generally has less effect on the thermal performance of the blend compared with that of JP-8. There is no large temperature difference between the fuels at the higher $\% \Delta P$ and $F / A\left(\Delta T=T_{\text {fuel blend }}-T_{\mathrm{JP}-8}=\sim 20-50^{\circ} \mathrm{F}\left(11-27^{\circ} \mathrm{C}\right)\right)$ where there are larger differences at higher inlet temperatures and pressures; however, a small change in temperature can have a major impact on the turbine life and efficiency; so these effects must be taken into consideration when selecting an alternative turbine engine fuel.

Plotting the combustor exhaust rake temperature differences versus the inlet pressure and $F / A$ (Figure 5) displays a 

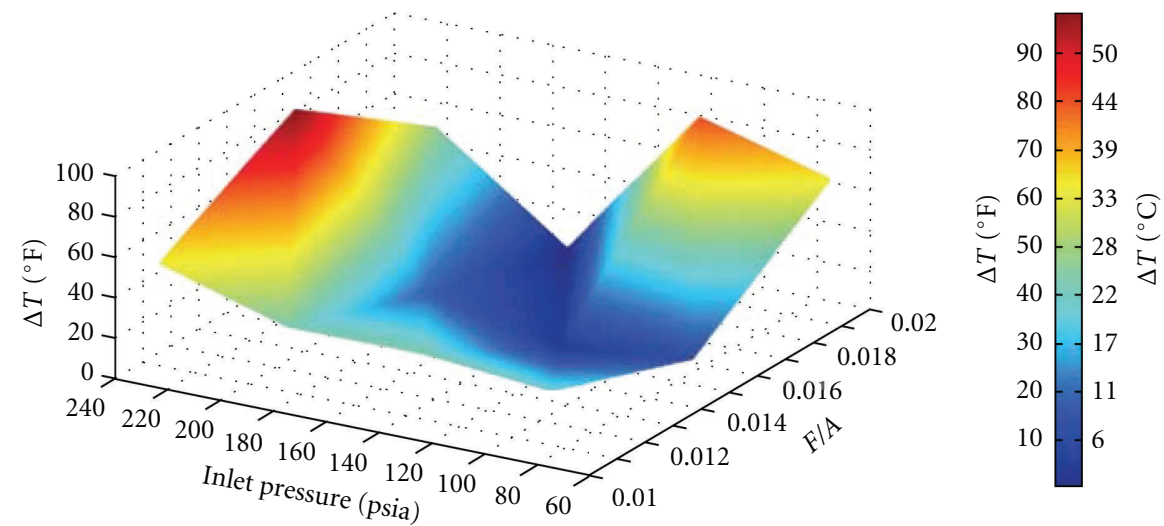

FIGURE 5: Combustor exhaust rake temperature differences $\left(\Delta T=T_{\text {fuel blend }}-T_{\mathrm{JP}-8},{ }^{\circ} \mathrm{F}\right)$ versus inlet pressure and $F / A$ for $3 \% \Delta P$ for $100 \%$ FT fuel, showing pressure and $F / A$ combinations that improve thermal performance (warmer colors) $(1 \mathrm{MPa}=145 \mathrm{psia})$.
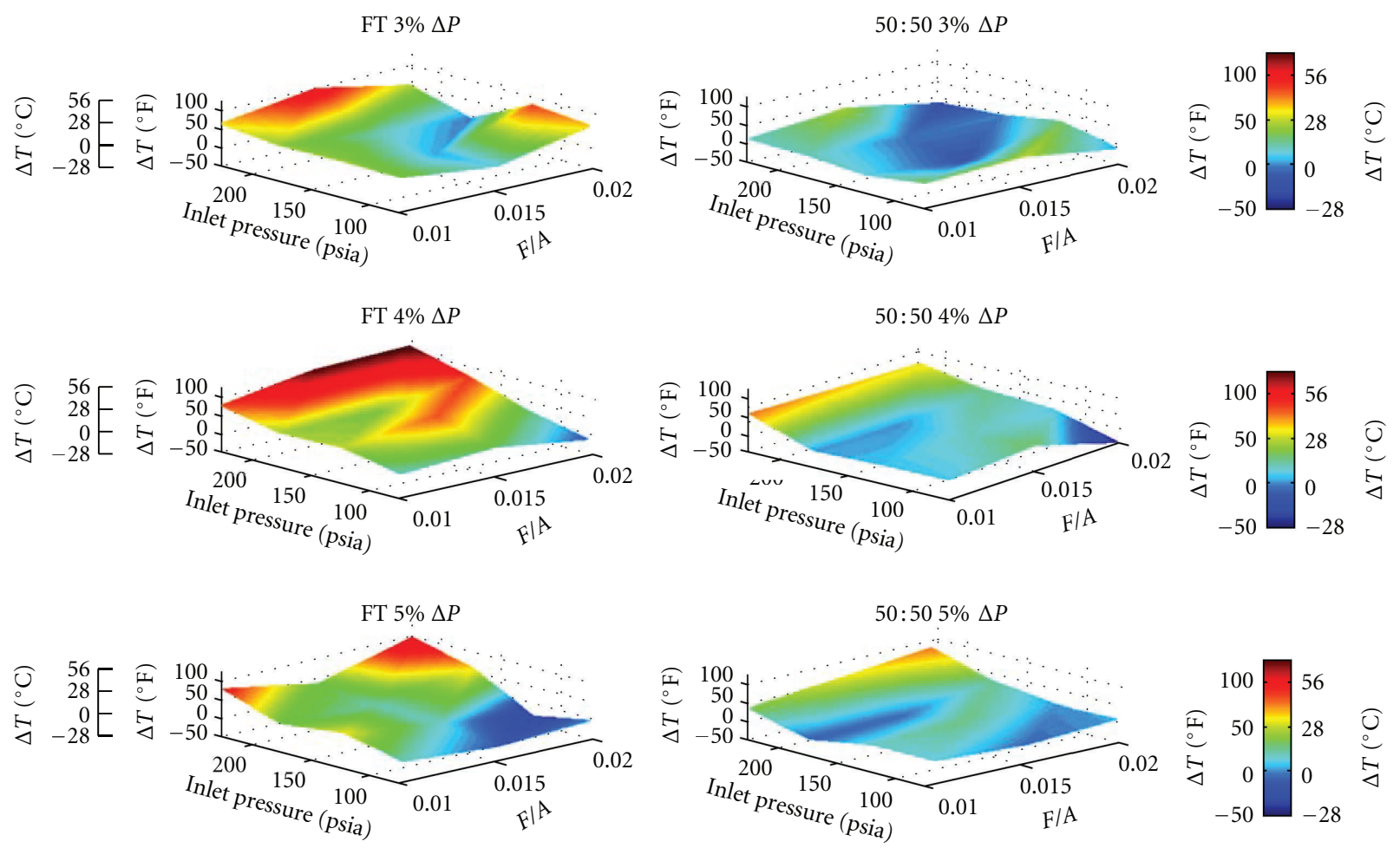

FIGURE 6: Combustor exit rake temperature differences $\left(\Delta T=T_{\text {fuel blend }}-T_{\mathrm{JP}-8},{ }^{\circ} \mathrm{F}\right)$ versus inlet pressure and $F / A$ for $3 \%$, $4 \%$, and $5 \% \Delta P$ for $100 \%$ and 50:50 FT fuel with respect to JP-8, showing pressure and $F / A$ combinations that improve thermal performance (warmer colors) $\left[\Delta T\left({ }^{\circ} \mathrm{F}\right)=1.8 \Delta T(\mathrm{~K})\right][1 \mathrm{MPa}=145 \mathrm{psia}]$.

minimum, above which the variables have a positive effect on the combustor performance of alternate fuels over JP-8 fuels.

Performing the same analysis for all $\% \Delta P$ conditions for both the 100\% and 50:50 FT fuel temperature difference data, it is clear that increasing the inlet pressure increases the temperature differences of the FT fuel compared to JP8. There also appears to be a peak in performance around $3-4 \% \Delta P$ for the alternate fuel in relation to the performance of JP-8 (illustrated in Figure 6).

The calculated flame temperatures based on emission data are outlined in Figure 7 for 225 psia $(1.55 \mathrm{MPa})$ at
$5 \% \Delta P$. As the inlet pressure and temperature is increased, there is a small increase in the flame temperature. The same trend is displayed with increasing $\% \Delta P$, although $\% \Delta P$ does not seem to affect the temperature differences between the fuels to a significant extent, (Figures 4 and 7). The $\% \Delta P$ trend is more pronounced than that of the changing inlet pressure and temperature, especially when increasing $F / A$. At higher $F / A$, there is a greater difference in flame temperatures between the fuels. The FT generally had higher flame temperatures than the JP-8, and the 50:50 blend temperatures fell between the FT and the JP- 8 fuel. 


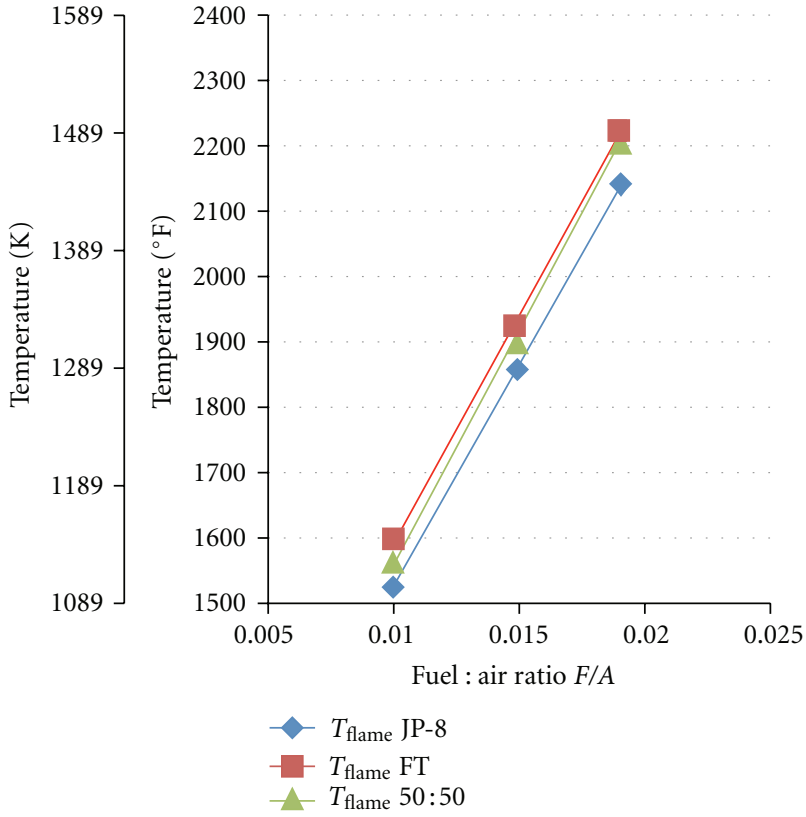

Figure 7: Calculated flame temperature $\left(T_{\text {flame }}\right)$ variation with $F / A$ and fuel composition for $(P, T)_{\text {inlet }}=\left[225 \mathrm{psia}(1.55 \mathrm{MPa}), 790^{\circ} \mathrm{F}\right.$ $(694 \mathrm{~K})]$ at $5 \% \Delta P$.

TABLE 3: Flame temperature differences $\left(T_{\text {fuel blend }}-T_{\text {JP- } 8}\right)\left({ }^{\circ} \mathrm{F}\right)$ for $(P, T)_{\text {inlet }}=\left[225 \mathrm{psia}(1.55 \mathrm{MPa}), 790^{\circ} \mathrm{F}(694 \mathrm{~K})\right]$.

\begin{tabular}{lcccc}
\hline Fuel & $F / A$ & \multicolumn{3}{c}{$\% \Delta P$} \\
& & $73(41)$ & $107(59)$ & $71(39)$ \\
\hline \multirow{2}{*}{ FT_JP-8 } & 0.010 & $73 \%$ & $63(35)$ \\
& 0.015 & $94(52)$ & $84(47)$ & $90(50)$ \\
\hline \multirow{2}{*}{$50: 50$ _JP-8 } & 0.020 & $34(19)$ & $105(58)$ & $33(18)$ \\
& 0.010 & $55(31)$ & $90(50)$ & $52(29)$ \\
& 0.015 & $43(24)$ & $41(23)$ & $70(39)$ \\
\hline
\end{tabular}

Values of $\Delta T$ in parenthesis are in Kelvins.

Similar trends are also displayed in Table 3 which contains the flame temperature differences between JP- 8 and the FT fuels. No significant trend was found to determine whether the FT or JP-8 performance had the dominant role in the flame temperature performance of the $50: 50$ blend.

There is some merit in considering how calculated flame temperature loci depend on the heat of combustion. There are two heat of combustion parameters of merit to consider: one based on mass and the other on volume. The ASTM D 4809-06 net heat of combustion for FT is $44.2(\mathrm{MJ} / \mathrm{kg})$ and $43.8(\mathrm{MJ} / \mathrm{kg})$ for JP-8, or about $1 \%$ change, and insufficient to collapse the flame temperatures into a single locus. However for flight purposes, energy per tank of fuel becomes a more meaningful parameter. Since JP-8 allowable American Petroleum Institute (API) gravity ranges from 37 to 51 (0.84 to $0.775 \mathrm{~kg} / \mathrm{L}$ ) and herein $0.8 \mathrm{~kg} / \mathrm{L}$ for JP-8 and $0.74 \mathrm{~kg} / \mathrm{L}$ for FT give $35 \mathrm{MJ} / \mathrm{mL}$ for JP-8 and $32.7 \mathrm{MJ} / \mathrm{mL}$ for FT, a $6.8 \%$ potential range decrease.

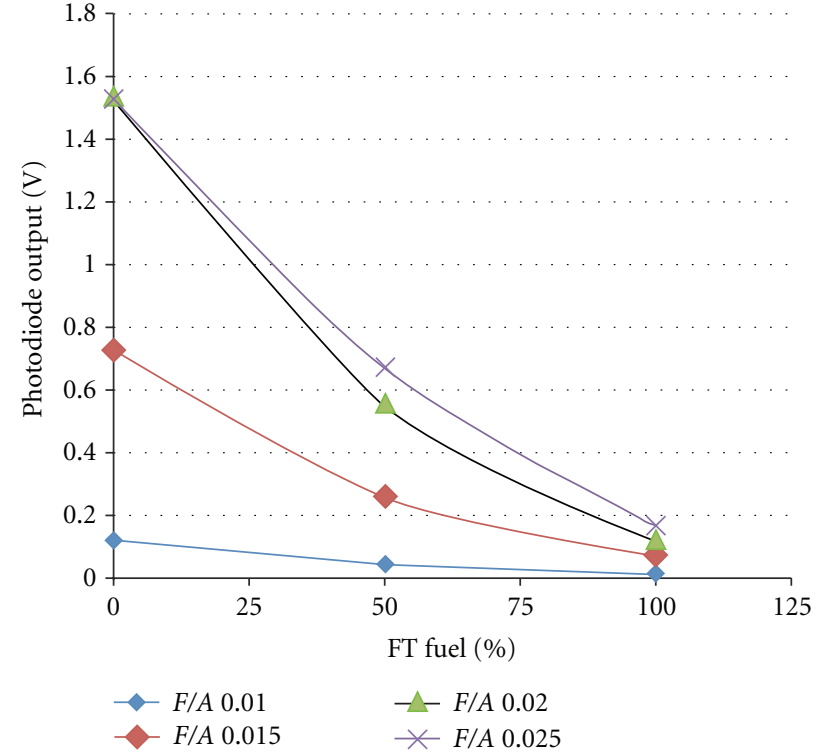

FIGURE 8: Variation in photodiode voltage output with \%FT fuel blends at various $F / A$ values for $75 \mathrm{psia}(0.52 \mathrm{MPa})$ at $5 \% \Delta P$. The decrease in luminosity as the $\%$ FT fuel approaches $100 \%$ is demonstrated [8].

\section{Emissions}

Emissions are discussed in [8] with some highlights as follows.

NOx emissions show a monotone decrease as $\% \Delta P$ increases, a monotone increase with $F / A$ ratio, and an increase with absolute pressure. The emissions are marginally lower for FT fueling compared to the JP-8.

CO emissions differences between JP-8 fuel and the 50\% and $100 \%$ FT blends show the FT fuel emitting more than JP-8 at higher $F / A$, but dipping lower at lower inlet pressures (P) [8].

Smoke number decreases as FT fueling increases, with more distinct decreases at higher F/A ratios. Photodiode luminosity increases with $F / A$ and decreases steadily with increasing $\% \Delta P$ and $\% \mathrm{FT}$ composition (Figure 8). The decreased luminosity of the $50: 50$ blend and the FT fuel show that they are cleaner burning fuels than JP-8 (Figure 9), as luminosity indicates carbon presence in the flames and therefore the potential for carbon deposits within or coming through the engine to be released into the environment. The decrease in luminosity as the fuel blend approaches full FT fuel implies that the radiative heat loss is also decreasing, as would liner temperature. This decrease occurs across increasing $\% \Delta P$ and decreasing $F / A$ as well, signifying lower heat losses, cleaner burning, and a higher exit temperature from the combustor engine.

Particulate emissions of any fuel are of utmost concern for both environmental and human health. Available data demonstrate the clear reduction in particulate emissions from FT fuel at all pressures and F/A values (Figure 10).

Generalizing emissions and performance trends, the data herein highlights the benefits of FT fuel and JP-8-FT blends. 
TABLE 4: Combustor outer and inner liner temperature, thermal difference data, and number and name of thermocouples (TCs) used to plot thermal profiles. ${ }^{\mathrm{a}, \mathrm{b}, \mathrm{c}}$

\begin{tabular}{|c|c|c|c|c|c|c|c|c|c|c|c|c|}
\hline \multirow{3}{*}{ TC } & & & & \multicolumn{3}{|c|}{$F / A=0.010$} & \multicolumn{3}{|c|}{$F / A=0.015$} & \multicolumn{3}{|c|}{$F / A=0.020$} \\
\hline & \multicolumn{3}{|c|}{ Unwrapped $^{\mathrm{d}}$} & JP-8 & FT & $50: 50$ & JP-8 & FT & $50: 50$ & JP-8 & FT & $50: 50$ \\
\hline & TC No. & $X$ & $\Theta$ & $\mathrm{Col} \mathrm{C}$ & $\mathrm{Col} \mathrm{G}$ & Col F & $\mathrm{Col} \mathrm{O}$ & $\mathrm{Col} \mathrm{K}$ & Col M & Col Q & $\mathrm{Col} \mathrm{V}$ & Col T \\
\hline \multicolumn{13}{|l|}{ Outer liner } \\
\hline & & & 0.00 & & & & & & & & & \\
\hline TOLAL & 22 & 0.94 & 0.20 & 817 & 825 & 825 & 852 & 850 & 846 & 882 & 873 & 881 \\
\hline TOLFL & 20 & 0.00 & 0.22 & 900 & 904 & 907 & 968 & 935 & 946 & 1030 & 971 & 1002 \\
\hline TOLML & 21 & 0.67 & 0.26 & 861 & 870 & 869 & 927 & 924 & 925 & 987 & 957 & 985 \\
\hline TOLMWA & 24 & 0.19 & 0.32 & 870 & 875 & 878 & 962 & 917 & 944 & 1027 & 960 & 1002 \\
\hline TOLFM & 27 & 0.00 & 0.34 & 899 & 902 & 908 & 983 & 944 & 956 & 1060 & 985 & 1024 \\
\hline TOLCA & 25 & 1.00 & 0.52 & 862 & 872 & 872 & 920 & 910 & 912 & 986 & 952 & 974 \\
\hline TOLAM & 28 & 0.94 & 0.58 & 814 & 825 & 825 & 852 & 851 & 850 & 888 & 874 & 886 \\
\hline TOLMR & 36 & 0.67 & 0.62 & 873 & 887 & 884 & 953 & 918 & 941 & 1013 & 955 & 996 \\
\hline TOLFR & 34 & 0.00 & 0.74 & 887 & 888 & 891 & 965 & 924 & 944 & 1016 & 956 & 1001 \\
\hline TOLMWI & 23 & 0.33 & 0.79 & 879 & 879 & 884 & 933 & 905 & 914 & 992 & 937 & 969 \\
\hline TOLAR & 37 & 0.84 & 0.86 & 831 & 843 & 843 & 877 & 872 & 874 & 917 & 906 & 922 \\
\hline TSWFD & 41 & 0.22 & 0.97 & 1218 & 1288 & 1280 & 1438 & 1469 & 1444 & 1544 & 1565 & 1581 \\
\hline TSWFT & 30 & 0.78 & 1.00 & 814 & 820 & 820 & 847 & 836 & 841 & 854 & 842 & 850 \\
\hline \multicolumn{13}{|l|}{ Inner liner } \\
\hline TILMWI & 38 & 0.50 & 1.20 & 897 & 908 & 906 & 994 & 969 & 976 & 1091 & 1023 & 1066 \\
\hline TILFR & 35 & 0.00 & 1.23 & 890 & 917 & 919 & 995 & 959 & 967 & 1075 & 1006 & 1050 \\
\hline TILMWO & 26 & 0.50 & 1.33 & 902 & 908 & 909 & 988 & 962 & 968 & 1096 & 1025 & 1071 \\
\hline TILCA & 29 & 1.00 & 1.50 & 1056 & 1065 & 1058 & 1229 & 1217 & 1219 & 1411 & 1326 & 1348 \\
\hline \multirow[t]{2}{*}{ TILFL } & 39 & 0.00 & 1.54 & 913 & 917 & 916 & 1002 & 970 & 981 & 1098 & 1030 & 1069 \\
\hline & & & 2.00 & & & & & & & & & \\
\hline
\end{tabular}

${ }^{a}$ Geometric position accuracy of thermocouple position coordinates is estimated at $\pm 1.5 \%$.

${ }^{\mathrm{b}}$ For nominal inlet pressure $225 \mathrm{psia}(1.55 \mathrm{MPa}), 80^{\circ} \mathrm{F}(700 \mathrm{~K})$, and $3 \%$ combustor pressure drop.

'Note: Col C, G, F, K, M, Q, V, and T are data set tracking identifiers.

${ }^{\mathrm{d}} X=x / L$ (which varies from 0 to 1 ), where $x$ is the TC position measured from the liner inlet and $L$ is the overall liner length.

$\Theta=$ circumferential TC position measured over the liner outside $y / L_{\theta}(0$ to 1$)$ and continuing back along the inside liner ( 1 to 2 ), where $L_{\theta}$ is half the unwrapped liner "width." The normalized unwrapped coordinate $(X, \Theta)$ is the TC location $(x, y)$.

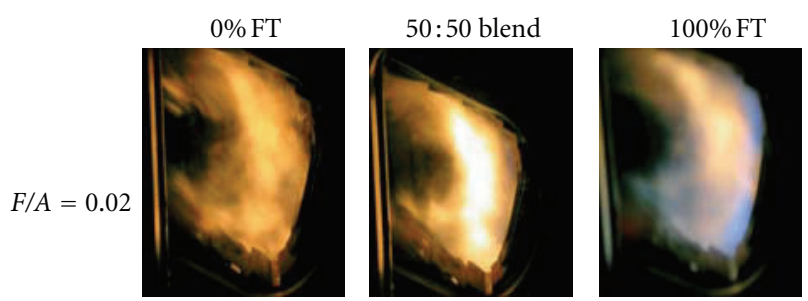

Figure 9: Digital camera photographs showing flame changes with changes in fuel blend at $F / A=0.020$. The JP-8 fuel is visibly more luminous $[6,8]$.

Such fueling produces fewer particulates, less smoke, and a lower thermal impact on the combustor hardware, which plays a significant role to extending the life of the component. A general rule is that every $10^{\circ} \mathrm{F}\left(5.5^{\circ} \mathrm{C}\right)$ of lower combustor temperature increases its life by $25 \%$ [6].

\section{Conclusions}

The data and analysis of alternate fuel performance of Combustor A show lower average liner temperatures and higher flame and average combustor outlet temperatures with increasing FT relative to JP- $8+100$ fueling. These higher temperatures affect turbine efficiency and blade/vane life. They are undercorrected based on the FT fuel higher heat of combustion per unit mass $(\mathrm{MJ} / \mathrm{kg})$ and overcorrected based on the heat of combustion per unit volume $(\mathrm{MJ} / \mathrm{mL})$. Thus, the engine would not be running at higher F/A. A more accurate way to assess how these outlet temperatures will affect the turbine life would be to look at the pattern factor of the exhaust temperatures.

Sidewall temperatures depend mainly on $F / A$ for performance decreasing in temperature from the FWD to MID and increasing in temperature from the MID to AFT. The unwrapped liner temperature data show that the blend and the FT fuel run hotter than JP-8+100 at lower $F / A$, but cooler at $F / A$ above $\sim 0.015$. At the higher $F / A$ values the FT fuel temperature differs more so from the JP- $8+100$ than the blend. Peak liner temperatures also increase with increasing $F / A$ and $\% \Delta P$ but seem unaffected by the type of fuel blend to a significant extent. Lower liner temperatures result from decreased radiative heat transfer from reduced aromatic content. 


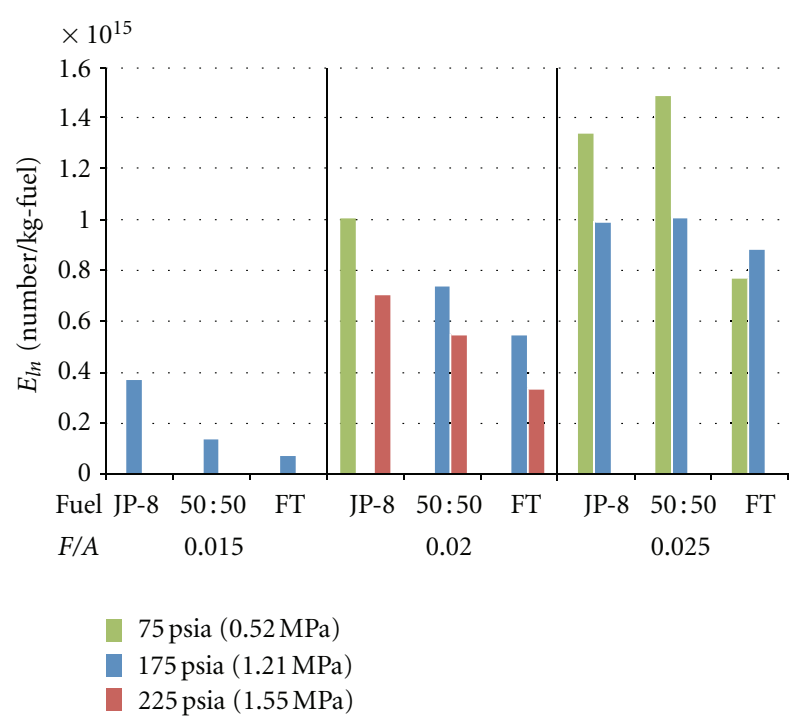

Figure 10: Particulate emissions number index variations with test pressure and F/A for JP-8, 50:50 FT blend and FT fueling. (Note: test data set incomplete at 75 and $225 \mathrm{psia}(0.52$ and $1.55 \mathrm{MPa})$ for $F / A=0.015$ and at 225 psia for $F / A=0.025)[6,8]$.

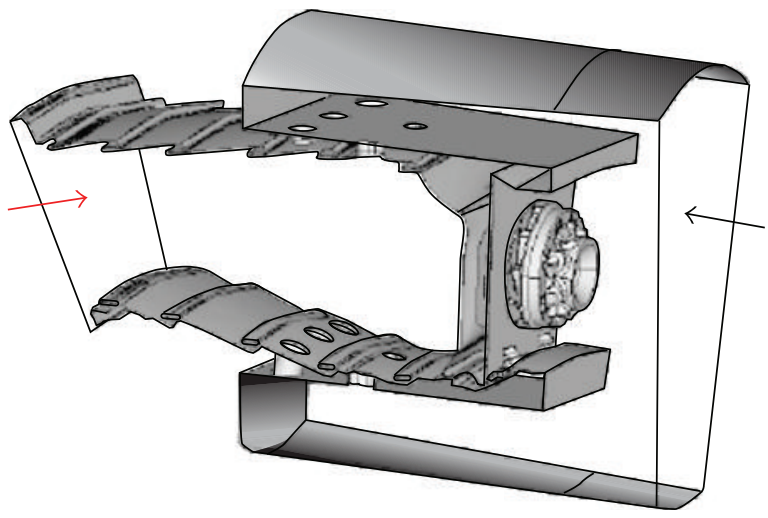

Figure 11: Combustor A geometry. One of the three combustion sections of AFRL/WPAFB test sector: (i) total air flow into the sector (black arrow), (ii) exit pressure at the sector exit plane (red arrow), and (iii) fuel droplet specification (not shown).

The $100 \%$ FT fuel tends to run at higher exhaust temperatures compared to the JP-8+100 and 50:50 blend fuels, with a similar trend for flame temperature. Overall, increasing $F / A$ and $\% \Delta P$ increase the thermal performance of the combustor, which will almost always occur unless there is a decrease in the efficiency of combustion.

The three-cup sector data herein demonstrate that $100 \%$ SPK-FT fuel and blends with JP- $8+100$ fueling produce less particulates and less smoke and have a lower thermal impact on the combustor hardware, which plays a significant role in extending the life of the component.

\section{Appendix}

Illustrated herein are the following.

(1) CFD sector element configuration: details are proprietary. CFD results are provided in [5] (Figure 11).

(2) Example of tabulated temperature data and associated normalized liner coordinates are presented in [6] (Table 4).

\section{References}

[1] Federal Aviation Administration and December 2011, "Press Release-FAA Announces Alternative Energy Investments For Cleaner, More Sustainable Jet Fuel," http://www.faa.gov/news/ press_releases/news_story.cfm?newsId $=13254$.

[2] J. DiMascio, Aerospace Daily \& Defense Report, vol. 240, no. 45, The McGraw-Hill Companies, 2011.

[3] The Wall Street Journal, "The Cellulosic Ethanol Debacle," REVIEW \& OUTLOOK, 2011, http://online.wsj.com/article/ SB10001424052970204012004577072470158115782.html?mod =WSJ_Opinion_AboveLEFTTop.

[4] R. J. Batt, J. A. McMillan, and I. P. Bradbury, "Lubricity additives-performance and no-harm effects in low sulfur fuels," SAE Technical Paper 961943, Diesel Performance and Additives, 1996.

[5] R. Ryder, R. C. Hendricks, M. L. Huber, and D. T. Shouse, "Computational analysis of dynamic SPK(S8)-JP-8 fueled combustor-sector performance," in Proceedings of the 13th International Symposium on Transport Phenomena and Dynamics of Rotating Machinery (ISROMAC 13 '10), Honolulu, Hawaii, USA, April 2010.

[6] D. T. Shouse, C. Neuroth, R. C. Hendricks et al., "Alternatefueled combustor-sector performance," in Proceedings of the 13th International Symposium on Transport Phenomena and Dynamics of Rotating Machinery (ISROMAC13 '10), Monana Surfrider Hotel, Honolulu, Hawaii, USA, April 2010.

[7] T. J. Bruno and E. Baibourine, "Comparison of biomass-derived turbine fuels with the composition-explicit distillation curve method," Energy and Fuels, vol. 25, no. 4, pp. 1847-1858, 2011.

[8] N. T. Saxena, A. E. Thomas, D. T. Shouse et al., "Alternatefueledcombustor-sector emissions," in Submitted to Proceedings of the 14th International Symposium on Transport Phenomena and Dynamics of Rotating Machinery (ISROMAC14 '12), 2012. 

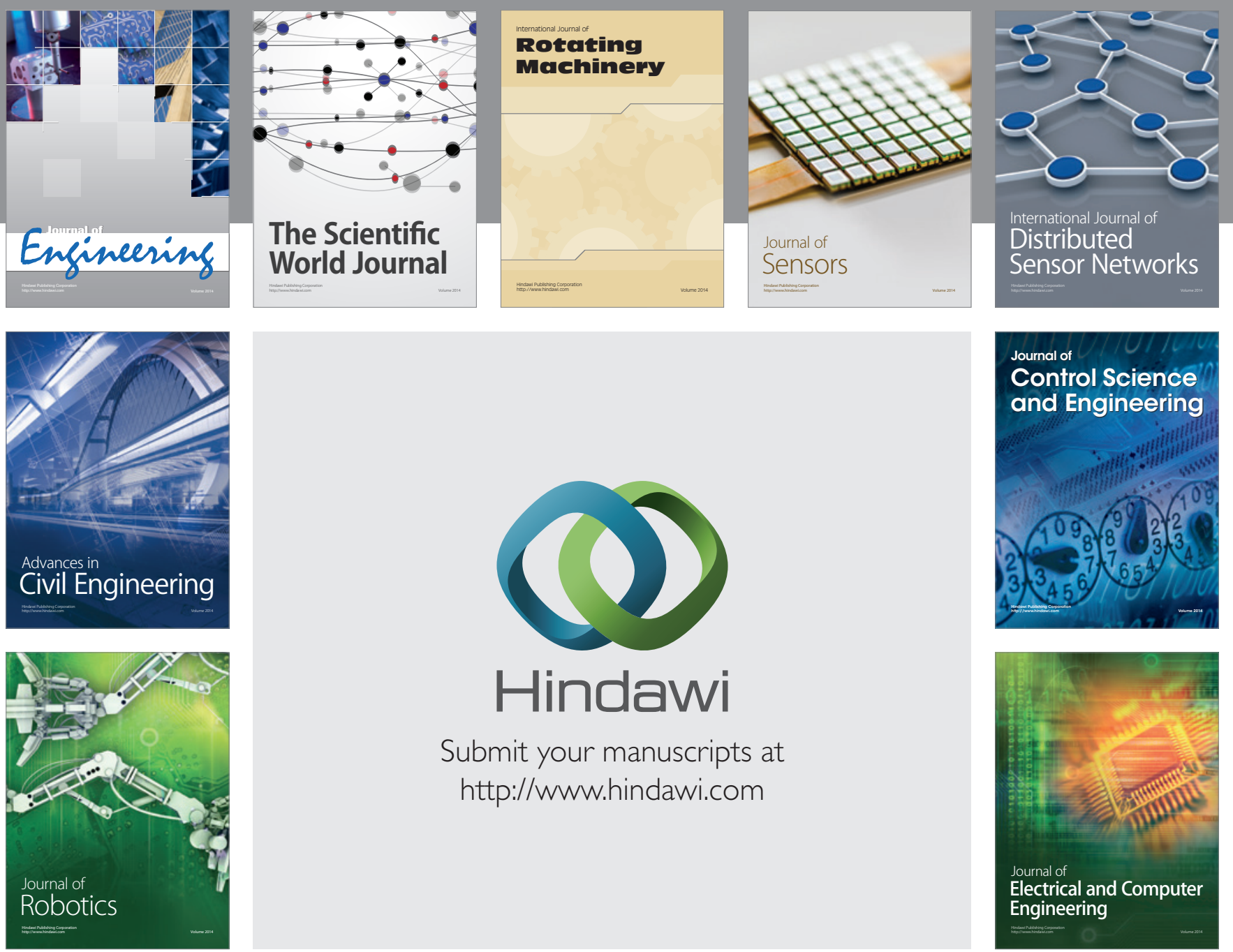

Submit your manuscripts at

http://www.hindawi.com
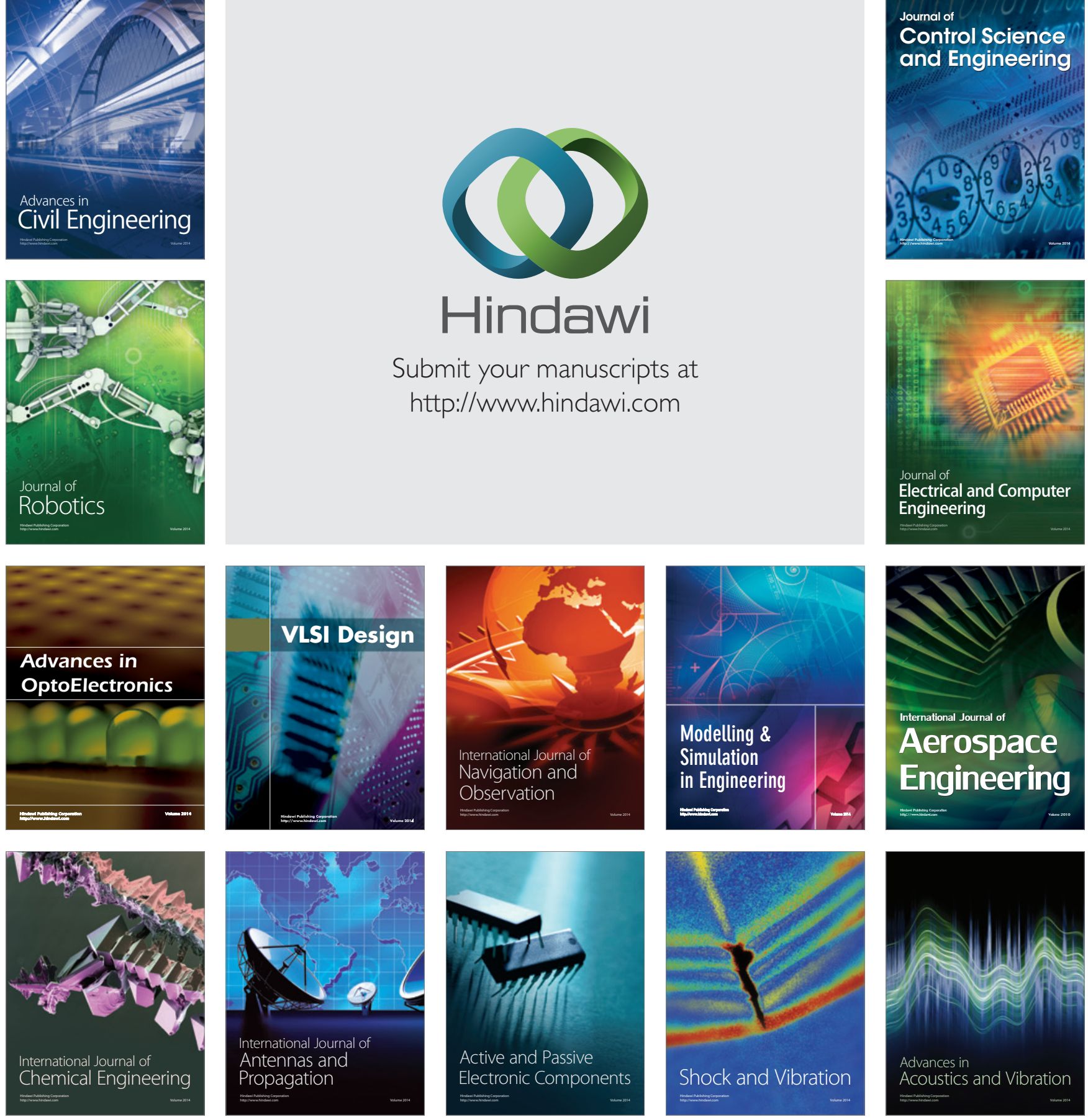